\title{
Defining the inherent stability of degenerative spondylolisthesis: a systematic review
}

\author{
Andrea M. Simmonds, MD, FRCSC, ${ }^{1}$ Y. Raja Rampersaud, MD, FRCSC, ${ }^{2}$ \\ Marcel F. Dvorak, MD, FRCSC, ${ }^{1}$ Nicolas Dea, MD, MSc, FRCSC, ${ }^{3}$ Angela D. Melnyk, MASc, ${ }^{1}$ and \\ Charles G. Fisher, MD, MHSc, FRCSC ${ }^{1}$
}

\begin{abstract}
${ }^{1}$ Department of Orthopaedics, Division of Spine, University of British Columbia, Vancouver, British Columbia; ${ }^{2}$ Division of Orthopaedic Surgery, Toronto Western Hospital, University Health Network, University of Toronto, Ontario; and ${ }^{3}$ Division of Neurosurgery, Department of Surgery, Université de Sherbrooke, Quebec, Canada
\end{abstract}

\begin{abstract}
OBJECT A range of surgical options exists for the treatment of degenerative lumbar spondylolisthesis (DLS). The chosen technique inherently depends on the stability of the DLS. Despite a substantial body of literature dedicated to the outcome analysis of numerous DLS procedures, no consensus has been reached on defining or classifying the disorder with respect to stability or the role that instability should play in a treatment algorithm. The purpose of this study was to define grades of stability and to develop a guide for deciding on the optimal approach in surgically managing patients with DLS.
\end{abstract}

METHODS The authors conducted a qualitative systematic review of clinical or biomechanical analyses evaluating the stability of and surgical outcomes for DLS for the period from 1990 to 2013. Research focused on nondegenerative forms of spondylolisthesis or spinal stenosis without associated DLS was excluded. The primary extracted results were clinical and radiographic parameters indicative of DLS instability.

RESULTS The following preoperative parameters are predictors of stability in DLS: restabilization signs (disc height loss, osteophyte formation, vertebral endplate sclerosis, and ligament ossification), no disc angle change or less than 3 $\mathrm{mm}$ of translation on dynamic radiographs, and the absence of low-back pain. The validity and magnitude of each parameter's contribution can only be determined through appropriately powered prospective evaluation in the future. Identifying these parameters has allowed for the creation of a preliminary DLS instability classification (DSIC) scheme based on the preoperative assessment of DLS stability.

CONCLUSIONS Spinal stability is an important factor to consider in the evaluation and treatment of patients with DLS. Qualitative assessment of the best available evidence revealed clinical and radiographic parameters for the creation of the DSIC, a decision aid to help surgeons develop a method of preoperative evaluation to better stratify DLS treatment options.

http://thejns.org/doi/abs/10.3171/2014.11.SPINE1426

KEY WORDS degenerative lumbar spondylolisthesis; stability; qualitative systematic review; restabilization; surgical technique

$\mathrm{D}$ EGENERATIVE lumbar spondylolisthesis (DLS) is a common condition that usually occurs at the L4-5 level, seldom presents before the 5th decade, predominates in women, and often presents with spinal steno- sis and an anterior translation up to $30 \%$ of the vertebral body width. Its pathology differs widely among patients; diverse clinical and radiographic presentations exist. Patients may have back pain or leg pain or both. Radiographically,

\footnotetext{
ABBREVIATIONS DLS = degenerative lumbar spondylolisthesis; DSIC = degenerative spondylolisthesis instability classification; MeSH = Medical Subject Headings. SUBMITTED February 17, 2014. ACCEPTED November 4, 2014. INCLUDE WHEN CITING Published online May 15, 2015; DOI: 10.3171/2014.11.SPINE1426.

DISCLOSURE The authors report no conflict of interest concerning the materials or methods used in this study or the findings specified in this paper. Dr. Fisher has received royalties from Medtronic; is a consultant for Medtronic and NuVasive; has speaking and/or teaching arrangements with Medtronic, AOSpine, and NuVasive; has received research support from Medtronic; has received grants from OREF; and has received fellowship support from Medtronic, AOSpine, and the British Columbia government. Dr. Dvorak has received royalties from Medtronic; is a consultant for Medtronic; has speaking and/or teaching arrangements with Medtronic, AOSpine, and Synthes; has received trips and travel from Medtronic, AOSpine, and Synthes; has received endowments from the Paetzold Chair; has received research support from Medtronic; has received grants from Rick Hansen Institute, CIHR, NSERC, and Wings for Life; has received fellowship support from Medtronic, AOSpine, and the British Columbia Ministry of Health; holds a patent with Medtronic; and has received support from Medtronic and DePuy/Synthes for non-study-related clinical or research effort. Dr. Rampersaud is a consultant for Medtronic.
} 
DLS varies in the magnitude of slip, disc and facet degeneration, and motion at the segment on dynamic views. ${ }^{2,11}$, $25,53,56$

Dupuis et al. described instability in DLS as abnormal movement exhibited by a lumbar motion segment. ${ }^{19}$ The radiographic findings of disc height, sagittal disc angle, slip magnitude, facet joint orientation, severity of degenerative change, and presence of facet effusion are well described in the literature. However, no consensus has been reached on the value of these parameters in determining segmental stability, despite a large volume of studies dedicated to the preoperative assessment of patients presenting with DLS.

Degenerative lumbar spondylolisthesis has been investigated extensively from a management perspective, ${ }^{41,56,58}$ and there is strong evidence to support surgical intervention. ${ }^{47,58,59}$ However, it is not clear which surgery should be used to treat DLS, and there is no agreement on the role that instability should play in the treatment algorithm. It seems prudent to define symptomatic DLS in terms of stability to better target the optimal surgical technique and implant construct from an outcome and cost perspective.

No systematic review of the best available evidence has been completed as regards the treatment of stable and unstable DLS. The ability to quantify stability using clinically relevant parameters would allow surgeons to determine an individualized, patient-specific surgical approach. Moreover, greater treatment and outcome consistency using comprehensive terminology would optimize prospective research.

Our primary objective in the present study was to identify measurable preoperative clinical and radiographic variables that would define instability in DLS. A secondary objective was to evaluate clinical studies for factors that would help determine which levels of unstable pathology would benefit from decompression alone, decompression with posterolateral fusion, or decompression with posterolateral fusion and interbody fusion. Lastly, we developed a guide for choosing the optimal surgical technique in managing DLS.

\section{Methods \\ Search Strategy}

A systematic search of the English literature pertaining to DLS was undertaken in consultation with a professional librarian. MEDLINE and EMBASE databases were searched for data published from 1990 to 2013. The subject headings (MeSH [Medical Subject Headings]) in both databases were used in conjunction with key word variants to build gold-standard search strategies, which were then run on March 7, 2013. Variant terms used in the search included "spondylolisthesis" [MeSH], "spondylolisthesis" [keyword search], "lumbar vertebrae" [MeSH] (and their key word variants), "degenerative," and spinal stenosis" [MeSH]. Important references from each paper were reviewed for related studies and for gray literature not found initially in MEDLINE or EMBASE. All the papers found in both databases were then imported into a reference management program (RefWorks), and duplicate studies were examined and placed into exclusion files. Additional articles that may have been initially missed in the MEDLINE and EMBASE searches were subsequently added.

\section{Inclusion and Exclusion Criteria}

We included biomechanical studies investigating possible factors associated with the stability of DLS and/or randomized controlled trials, comparative observational studies, or large case series investigating the surgical management of DLS by comparing 1) fusion to decompression and/or 2) instrumented to noninstrumented fusion and/or 3) posterolateral fusion to posterolateral fusion augmented with interbody fusion. To be included in our review, comparative studies had to have at least 5 patients in each study group, retrospective case series had to have 100 or more patients, and prospective case series had to have 40 or more patients. These inclusion parameters were chosen to safeguard objectivity, based on the quality of the literature available and previously used criteria. ${ }^{38,41}$

Studies were excluded if they investigated spinal stenosis in the absence of DLS or if it was impossible to separately analyze patients with DLS from another patient population. Comparative studies were excluded if they contained patients with tumors, isthmic spondylolisthesis, scoliosis, spinal fractures, or previous spine surgery. Degenerative spondylolisthesis in the cervical or thoracic spine was excluded as well.

\section{Evidence Categorization}

Included studies were divided into 2 categories: biomechanical and clinical/radiographic. Clinical studies were critically evaluated by 2 independent reviewers (A.M.S. and C.G.F.) according to the Grades of Recommendation, Assessment, Development, and Evaluation (GRADE) criteria proposed by Schünemann et al. ${ }^{54}$ Biomechanical studies were reviewed by a biomedical engineer (A.D.M.) and also graded according to their quality of evidence.

To facilitate defining DLS in terms of stability, results from the literature were categorized under the headings of patient factors, dynamic radiographs, facet joint orientation and tropism, facet joint effusion, restabilization signs, and disc height (Table 1). The findings were used to generate a quantitative scheme based on stability (Table 2). Examples of each stability type are illustrated in Figs. 1-3.

Our secondary objective was aided by the evaluation of clinical studies for factors that might help to determine which disease types, based on stability grading, would benefit from decompression alone, decompression with posterolateral fusion, or decompression with posterolateral fusion and interbody fusion. These findings were used to create a provisional surgical decision guide for the recommended surgical technique (Table 3).

\section{Results \\ Degenerative Lumbar Spondylolisthesis Stability}

A total of 696 abstracts were identified through MEDLINE and EMBASE searches. All abstracts were reviewed, and the complete text of each potentially relevant article was obtained. Another 9 potential articles were identified from a hand search of bibliographies. Five biomechanical ${ }^{10,16,27,28,31}$ and 40 clinical and/or radiographic 
TABLE 1. Parameters used to assess stability in the included biomechanical and clinical studies evaluating patients with DLS

\begin{tabular}{|c|c|c|}
\hline Parameter & Definition & Comments \\
\hline Patient factors & Age, sex, occupation, \& BMI & $\begin{array}{l}\text { These variables assessed in several papers for correlation w/ } \\
\text { stability at a given segment; none were found to have a strong } \\
\text { association w/ instability }\end{array}$ \\
\hline Dynamic radiographs & $\begin{array}{l}\text { Change in disc angle or translation w/ flexion or exten- } \\
\text { sion radiographs, compared to neutral radiographs }\end{array}$ & $\begin{array}{l}\text { Various measurement criteria used to define instability, including } \\
\text { change in angle }>8^{\circ}-10^{\circ} \text {, change from lordotic angle to kyphotic } \\
\text { angle, and translation }>1.25 \mathrm{~mm}\end{array}$ \\
\hline Facet joint orientation & Angle btwn coronal plane \& plane of the facet joint & $\begin{array}{l}\text { Sagittally orientated facet joints have been shown to be associated } \\
\text { w/ DLS; their role in the disease \& particularly in the stability of a } \\
\text { diseased segment is controversial }\end{array}$ \\
\hline Facet joint effusion & $\begin{array}{l}\text { T2-weighted MRI assessed for presence \& amount of } \\
\text { facet joint fluid; measured as a facet fluid index }\end{array}$ & $\begin{array}{l}\text { Several calculation techniques exist for facet joint fluid effusion } \\
\text { measurement; effusion size appears to have a linear correlation } \\
\text { w/ instability }\end{array}$ \\
\hline Restabilization signs & $\begin{array}{l}\text { Osteophyte formation, vertebral endplate sclerosis, \& } \\
\text { ligament ossification have been described as signs of } \\
\text { restabilization }\end{array}$ & $\begin{array}{l}\text { Several parameters exist that may indicate restabilization of a given } \\
\text { segment }\end{array}$ \\
\hline Disc height & $\begin{array}{l}\text { Disc height as a percentage of either disc width or verte- } \\
\text { bral body height }\end{array}$ & Assessed in several studies as a potential indicator of stability \\
\hline
\end{tabular}

$\mathrm{BMI}=$ body mass index.

papers ${ }^{1,3-5,7,9,11-13,15,18,20,22-24,29,30,32-34,36,37,39,40,42-47,49,52,53,57}$ were selected for study inclusion and graded for quality of evidence (Tables 4 and 5 list studies with evidence graded as low or higher). Twenty-two studies had very low quality evidence, 15 had low quality evidence, 3 had moderate quality evidence, and none had high quality evidence.

\section{Patient Factors}

Most of the identified studies failed to demonstrate a significant correlation between stability in DLS and patient age, sex, occupation, or body mass index. . $^{3,22,30,42-46,49}$ Pearson et al. found that a significantly smaller number of women with DLS showed radiographic instability, as compared with their male counterparts. ${ }^{47}$ Matsunaga et al. found that patients with occupations demanding repetitive anterior flexion of the lumbar spine showed a significant increase in the likelihood of slip progression when they were managed nonoperatively. ${ }^{44}$ Several studies used the presence of leg-dominant symptoms as a predictor of stability, with low-back pain as the dominant or secondary presenting feature being a marker of instability. ${ }^{32,49}$ None of the identified patient factors showed a strong association with instability. All studies (11) that investigated the relationship between patient factors and stability in DLS had a very low to low quality of evidence.

\section{Dynamic Radiographs}

Most studies indicated that dynamic radiographs are an important part of a preoperative workup and offer insight into stability at a given segment. Traditionally, authors use a disc angle change $>10^{\circ}$ or change in translation $>3 \mathrm{~mm}$, from standing or supine radiographs to dynamic radiographs, as a sign of instability. ${ }^{3,7-9,13,15,17,25,26,31,48}$ In a study with low quality evidence, Kanayama et al. showed that dynamic flexion radiographs may be the most important images for determining instability. ${ }^{31}$ These authors proposed that lordosis on flexion radiographs (compared with neutral position radiographs) is a sign of a stable segment, whereas change from lordosis to kyphosis with forward bending shows instability at a given level. In Blumenthal et al.'s study with low quality evidence, a translation > $1.25 \mathrm{~mm}$ of a DLS segment on dynamic radiographs was a significant risk factor for instability. ${ }^{7}$ Several other studies that did not meet our inclusion criteria also described translation as a marker of instability. ${ }^{8,25,48,58}$ Dynamic radiographs appear to be an important tool for assessing sta-

TABLE 2. Degenerative spondylolisthesis instability classification scheme: a qualitative guide for the preoperative assessment of stability in patients with DLS

\begin{tabular}{|c|c|c|c|}
\hline Parameter & Type I, Stable & Type II, Potentially Unstable & Type III, Unstable \\
\hline Low-back pain & None or very mild & Primary or secondary complaint & Primary or secondary complaint \\
\hline Restabilization & $\begin{array}{l}\text { Restabilization signs, grossly narrowed disc } \\
\text { height }\end{array}$ & $\begin{array}{l}\text { Some restabilization signs, reduced disc } \\
\text { height }\end{array}$ & $\begin{array}{l}\text { No restabilization signs, normal to slightly } \\
\text { reduced disc height }\end{array}$ \\
\hline Disc angle & $\begin{array}{l}\text { Lordotic disc angle on flexion radiographs } \\
\text { or }<3 \mathrm{~mm} \text { of translation on dynamic } \\
\text { films* }\end{array}$ & $\begin{array}{l}\text { Neutral disc angle on flexion radiographs or } \\
3-5 \mathrm{~mm} \text { of translation on dynamic films }\end{array}$ & $\begin{array}{l}\text { Kyphotic disc angle on flexion radiographs } \\
\text { or }>5 \mathrm{~mm} \text { of translation on dynamic } \\
\text { films }^{*}\end{array}$ \\
\hline Joint effusion & No facet joint effusions on MRI & $\begin{array}{l}\text { Facet joint effusion on MRI w/o joint distrac- } \\
\text { tion }\end{array}$ & Large facet joint effusion on MRI \\
\hline
\end{tabular}

\footnotetext{
* Dynamic films include flexion and extension radiographs or supine to standing radiographs.
} 

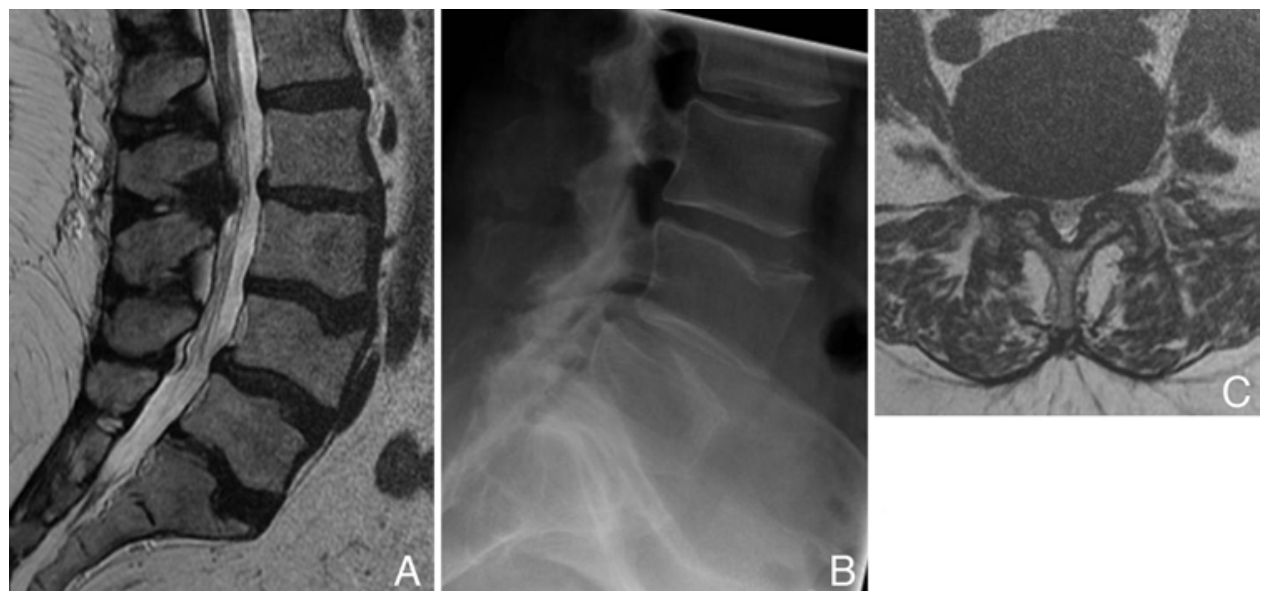

FIG. 1. Imaging samples of a patient with Type I (stable) L4-5 DLS. Note the restabilization signs, disc height loss, stable slip translation on standing radiographs ( $\mathrm{A}$ and $\mathrm{B}$ ), as well as the lack of facet joint effusion (C) on MRI.

bility. Several parameters exist for measurement, including change in disc angle and translation. Kanayama et al. proposed a simplified measurement tool that categorizes the segmental angle as lordotic, neutral, or kyphotic. ${ }^{31}$

\section{Facet Joint Orientation and Tropism}

Studies with very low quality evidence have suggested that increased sagittal orientation of the facet joints is associated with DLS. ${ }^{4,6,15,23,31,57}$ However, there is disagreement among the authors of these papers regarding the significance of facet joint orientation and tropism as they relate to the stability of a DLS segment. Kanayama et al. did not find that facet orientation correlated with angular instability. ${ }^{31}$ Cinotti et al. found an inverse relationship between the degree of sagittal orientation of the facet joints and the hypermobility of the spondylolisthetic vertebra. ${ }^{15}$ Grobler et al. found an association between higher sagittal orientation at L4-5 and DLS; they concluded that this association represents a developmental predisposition for DLS. ${ }^{23}$ Dai also suggested that facet joint tropism is a predisposing factor in DLS. ${ }^{18}$ However, Berlemann et al. contend that a sagittal orientation is unlikely to be a causative factor in DLS given the lack of correlation between facet orientation and advancing patient age; ${ }^{4}$ instead, they suggest that a remodeling of the joint due to hypertrophic degeneration is more likely. Furthermore, they did not find an association between facet joint tropism and the development of DLS. However, they did find a significant positive association between listhesis grade and more sagittally oriented facet joints. ${ }^{6}$ While sagittally oriented facet joints have been associated with DLS, their role in the development of the disease and especially in the stability of a diseased segment is controversial, based on current evidence.

\section{Facet Joint Effusion}

Facet joint effusion appears to have a linear correlation with the degree of instability at a given segment. ${ }^{13,39,46} \mathrm{To}$ measure this entity, Cho et al. used the facet fluid index, ${ }^{13}$
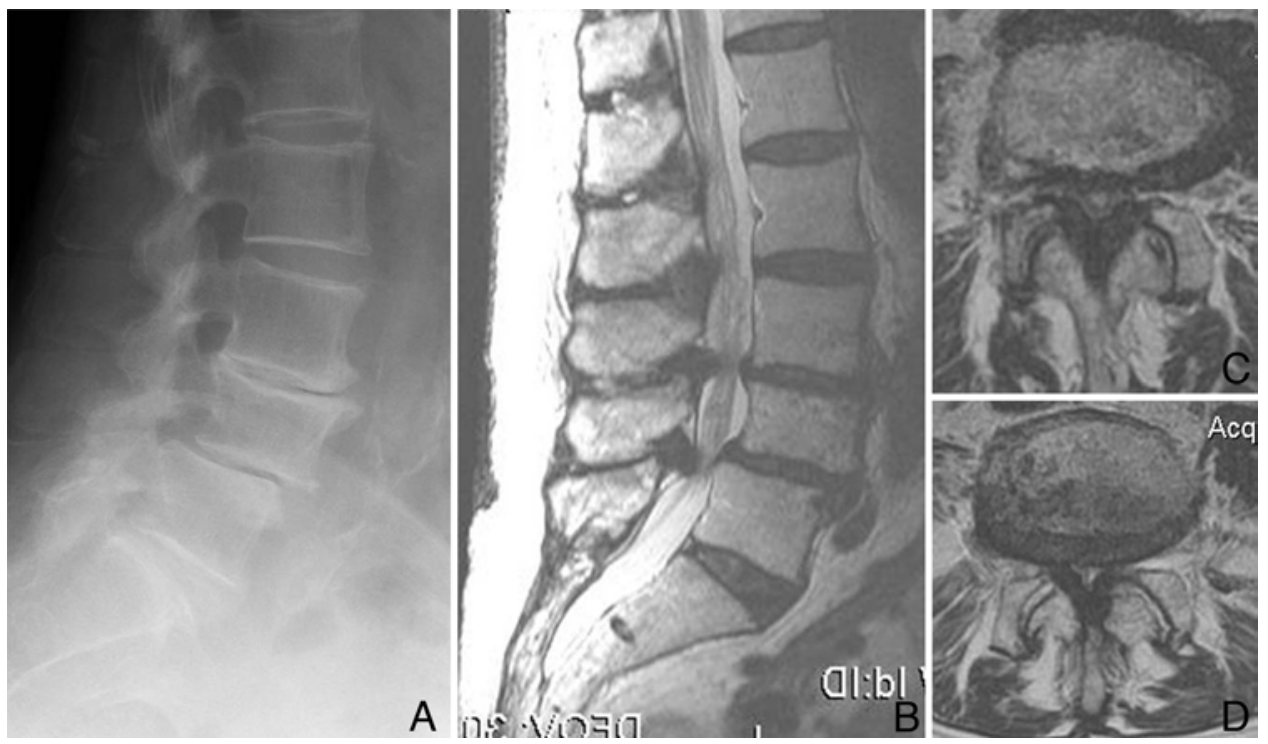

FIG. 2. Imaging samples of a patient with a Type II (potentially unstable) L4-5 DLS. Note the increase in slip translation on standing radiographs ( $A$ and $B$ ), moderate facet joint effusion on $M R I$ (C and $D)$, and presence of restabilization signs ( $A$ and $B)$. 

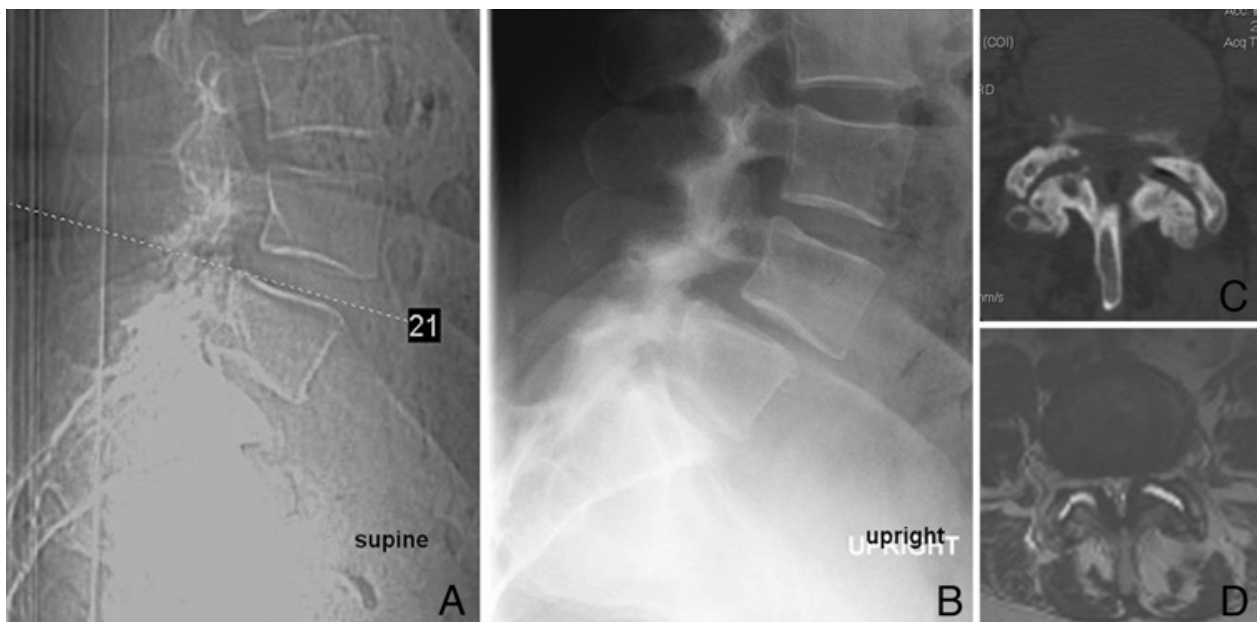

FIG. 3. Imaging samples of a patient with a Type III (unstable) L4-5 DLS. Note the increase in slip translation (A and B) on standing radiographs, large facet joint effusion (C and D) on MRI, and subtle restabilization signs (A-C).

which was defined as the sum of the facet fluid distance on the right and left sides divided by the sum of their average facet width on the right and left sides. Lattig et al..$^{39}$ and Oishi et al. ${ }^{46}$ measured the greatest distance between the apparent articular surfaces to determine facet effusion size. Lattig et al. found that, in general, mean effusions over $1.77 \mathrm{~mm}$ on either side were associated with instability, whereas Oishi et al. found unstable motion in patients with effusion sizes over $1.3 \mathrm{~mm}$. Several proposed but unvalidated calculation techniques exist for measuring facet joint fluid effusion. Although all studies (3) included in this analysis of facet joint effusion have a low to very low quality of evidence, they have indicated that the presence of a facet joint effusion, best seen on a supine axial MR image, appears to have a linear correlation with instability.

\section{Restabilization Signs}

Kirkaldy-Willis and Farfan described secondary changes in the affected segments leading to the restabilization of spondylolisthesis. ${ }^{35}$ Several other authors have echoed the concept of segmental stabilization from osteophyte formation, vertebral endplate sclerosis, and ligament ossification. Lattig et al. ${ }^{39}$ and Matsunaga et al. ${ }^{44}$ associated osteophytes with increased stability at the affected segments. However, Anderson et al. found that osteophyte size, when evaluated both categorically or as a continuous variable, was not correlated with either translational or angular motion on flexion and extension radiographs. ${ }^{3}$ The majority of studies have showed that restabilization can occur at a diseased segment, and thus increasing stability in DLS. There is no firm agreement on what parameters indicate a restabilized segment, but osteophyte formation, vertebral endplate sclerosis, and ligament ossification have been implicated in this process by very low quality evidence.

\section{Disc Height}

Controversy exists regarding the association between narrowed disc height and stability of the affected DLS segment. While several clinical and biomechanical studies have failed to show a significant correlation between the two, ${ }^{6,31,44}$ some studies with low quality evidence have showed decreased slip progression or have inferred stability with narrowed disc height. ${ }^{16,21}$ Despite the absence of conclusive evidence that disc space narrowing is directly associated with increased stability, there is enough evidence for it to be considered in the determination of stability at a given segment.

\section{Surgical Technique}

\section{Decompression Versus Decompression and Fusion}

Low to moderate quality evidence supports the historical understanding that decompression and fusion lead to

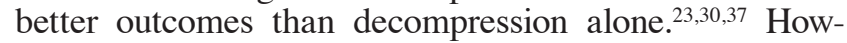
ever, as our understanding evolves, DLS is viewed as a more complex disease than previously assumed. More recent studies with low quality evidence have challenged the belief that all patients with DLS should be placed in a single study group. Several authors have stratified patients based on presumed stability and reevaluated the need for fusion. ${ }^{32,42,49,53}$ In these studies, it would appear that the 2 main selection criteria for selecting decompression alone in the DLS population were 1) leg-dominant symptoms and 2) Grade 1 DLS with $<3-5 \mathrm{~mm}$ of movement on loading or dynamic radiographs. ${ }^{32,42,52}$ Furthermore, Kim et al. found that in stable patients with leg-dominant symptoms, decompression alone is significantly more cost effective. ${ }^{33}$ While the literature is not conclusive at this point, there is some low quality evidence that decompression alone may be the optimal treatment in carefully selected patients with so-called stable DLS.

\section{Instrumented Versus Noninstrumented Fusion}

While instrumentation has been shown to increase fu-

TABLE 3. Proposed treatment guideline with stratification by stability grade

\begin{tabular}{ll}
\hline Type of Stability Grade & \multicolumn{1}{c}{ Treatment } \\
\hline I, stable & Decompression alone \\
\hline II, potentially unstable & Decompression \& posterior fusion \\
\hline III, unstable & $\begin{array}{c}\text { Decompression \& posterior fusion + interbody } \\
\text { fusion }\end{array}$ \\
\hline
\end{tabular}


TABLE 4. Summary on the 5 biomechanical articles included in the study, with the grade of evidence determined by an independent biomechanical engineer

\begin{tabular}{|c|c|c|c|c|c|c|}
\hline $\begin{array}{l}\text { Authors \& } \\
\text { Year }\end{array}$ & Article Title & $\begin{array}{l}\text { No. of Patients or } \\
\text { Motion Segments }\end{array}$ & Study Type & Outcomes & Critique of Evidence & $\begin{array}{l}\text { Grade of } \\
\text { Evidence }\end{array}$ \\
\hline $\begin{array}{l}\text { Crawford et } \\
\text { al., } 2001\end{array}$ & $\begin{array}{l}\text { Biomechanics of Grade } \\
\text { I degenerative lumbar } \\
\text { spondylolisthesis. Part 1: in } \\
\text { vitro model }\end{array}$ & $\begin{array}{l}3 \text { cadav- } \\
\text { eric spines, } 13 \\
\text { segments }\end{array}$ & $\begin{array}{l}\text { Cross- } \\
\text { sectional } \\
\text { cadaveric } \\
\text { (ex vivo) }\end{array}$ & $\begin{array}{l}\text { Effect of tissue sectioning } \\
\text { on spinal motion (rotation } \\
\quad \& \text { shear translation) }\end{array}$ & $\begin{array}{l}\text { Nonphysiological shear } \\
\text { loads, questionable } \\
\text { statistics }\end{array}$ & Low \\
\hline $\begin{array}{l}\text { Cagli et al., } \\
2001\end{array}$ & $\begin{array}{l}\text { Biomechanics of Grade } \\
\text { I degenerative lumbar } \\
\text { spondylolisthesis. Part 2: } \\
\text { treatment with threaded } \\
\text { interbody cages/dowels } \\
\text { and pedicle screws }\end{array}$ & $\begin{array}{l}7 \text { cadav- } \\
\text { eric spines, } 33 \\
\text { segments }\end{array}$ & $\begin{array}{l}\text { Cross- } \\
\text { sectional } \\
\text { cadaveric } \\
\text { (ex vivo) }\end{array}$ & $\begin{array}{l}\text { Effect of spine hardware on } \\
\text { ROM \& translation }\end{array}$ & $\begin{array}{l}\text { Low no. of specimens, } \\
\text { nonphysiological shear } \\
\text { loads, questionable } \\
\text { statistics }\end{array}$ & Low \\
\hline $\begin{array}{l}\text { Hasegewa et } \\
\text { al., } 2009\end{array}$ & $\begin{array}{l}\text { Biomechanical evaluation } \\
\text { of segmental instability } \\
\text { in degenerative lumbar } \\
\text { spondylolisthesis }\end{array}$ & $\begin{array}{l}41 \text { subjects, } 6 \\
\text { controls }\end{array}$ & $\begin{array}{l}\text { Case- } \\
\text { control (in } \\
\text { vivo) }\end{array}$ & $\begin{array}{l}\text { Difference in in vivo biome- } \\
\text { chanical parameters btwn } \\
\text { case \& control: stiffness, } \\
\text { neutral zone, absorption } \\
\text { energy }\end{array}$ & $\begin{array}{l}\text { Actual motion/force ap- } \\
\text { plied \& measured is not } \\
\text { clear, but comparisons } \\
\text { btwn groups should still } \\
\text { be valid }\end{array}$ & Moderate \\
\hline $\begin{array}{l}\text { Hasegawa et } \\
\text { al., } 2010\end{array}$ & $\begin{array}{l}\text { Facet joint opening in lumbar } \\
\text { degenerative diseases indi- } \\
\text { cating segmental instability }\end{array}$ & $\begin{array}{l}17 \text { DLS subjects, } \\
12 \text { stenosis } \\
\text { subjects }\end{array}$ & $\begin{array}{l}\text { Case- } \\
\text { control (in } \\
\text { vivo) }\end{array}$ & $\begin{array}{l}\text { Difference in in vivo biome- } \\
\text { chanical parameters btwn } \\
\text { case \& control: stiffness, } \\
\text { neutral zone, energy; } \\
\text { correlations w/ facet joint } \\
\text { degeneration }\end{array}$ & Small no. of subjects & Moderate \\
\hline $\begin{array}{l}\text { Kanayama et } \\
\text { al., } 2003\end{array}$ & $\begin{array}{l}\text { Intraoperative biomechani- } \\
\text { cal assessment of lumbar } \\
\text { spinal instability: validation } \\
\text { of radiographic parameters } \\
\text { indicating anterior column } \\
\text { support in lumbar spinal } \\
\text { fusion }\end{array}$ & 19 patients & $\begin{array}{l}\text { Prospective } \\
\text { cohort (in } \\
\text { vivo) }\end{array}$ & $\begin{array}{l}\text { In vivo spinal distraction } \\
\text { stiffness correlation w/ } \\
\text { radiographic measures of } \\
\text { instability }\end{array}$ & $\begin{array}{l}\text { Low no. of patients, cali- } \\
\text { bration of force-strain } \\
\text { spreader to measure } \\
\text { main outcome (stiffness) } \\
\text { was not adequately } \\
\text { described }\end{array}$ & Low \\
\hline
\end{tabular}

ROM = range of motion.

sion rates, 2-year follow-up results in most of the identified studies consistently showed no difference in clinical outcomes between patients treated with instrumented fusion and those treated with noninstrumented fusion..$^{14,20}$ Kimura et al. did find that postoperative low-back pain was significantly less in the instrumented fusion group and that the use of pedicle screws resulted in a lordotic angulation at the L4-5 level. ${ }^{34}$ Chen et al. found that instrumentation led to better clinical outcomes at an average of 58 months. ${ }^{12}$ Unfortunately, there is limited long-term follow-up among the studies. At this time, the studies (4) investigating instrumented versus noninstrumented fusion are low quality and suggest that there is no definite benefit to instrumented fusion.

Posterolateral Fusion Versus Posterolateral and Interbody Fusion

A limited amount of literature evaluates the role of interbody fusion as an adjunct to decompression and posterolateral fusion in patients with DLS. ${ }^{24,53} \mathrm{Ha}$ et al. highlighted the need for the stratification of patients based on stability and showed that interbody fusion could be a worthwhile adjunctive procedure in those with unstable $\mathrm{DLS}^{24}$

\section{Discussion}

In 2005, Resnick et al. published an extensive set of guidelines for the performance of fusion procedures for degenerative diseases of the lumbar spine, including stenosis and spondylolisthesis. ${ }^{50}$ These guidelines were updated in $2014,{ }^{51}$ and decompression plus posterolateral fusion was recommended in this patient population, but the authors noted that there was insufficient evidence to recommend a treatment guideline. Surgeons' understanding of DLS is evolving; thus, conventional evidence-based treatments are being challenged with less invasive and lower cost procedures. The controversy that exists regarding the treatment of patients with stable DLS is exemplified by a Web survey posted by the North American Spine Society in 2008. In this survey, Scioscia et al. noted that, for patients with stable DLS, the majority of respondents (41.7\%) still recommended decompression and fusion. ${ }^{55}$ However, the second most common recommendation $33.4 \%$ of respondents) was for decompression alone. If spine surgeons are to obtain higher quality evidence to guide the treatment of DLS, we must first establish a baseline of best available evidence around critical parameters and move forward with carefully planned prospective research.

While several authors have noted the importance of determining stability in a preoperative workup, there is no consensus on what constitutes the variables indicating stability or their specific weight or contribution to the magnitude of DLS stability. In addition, recent literature 


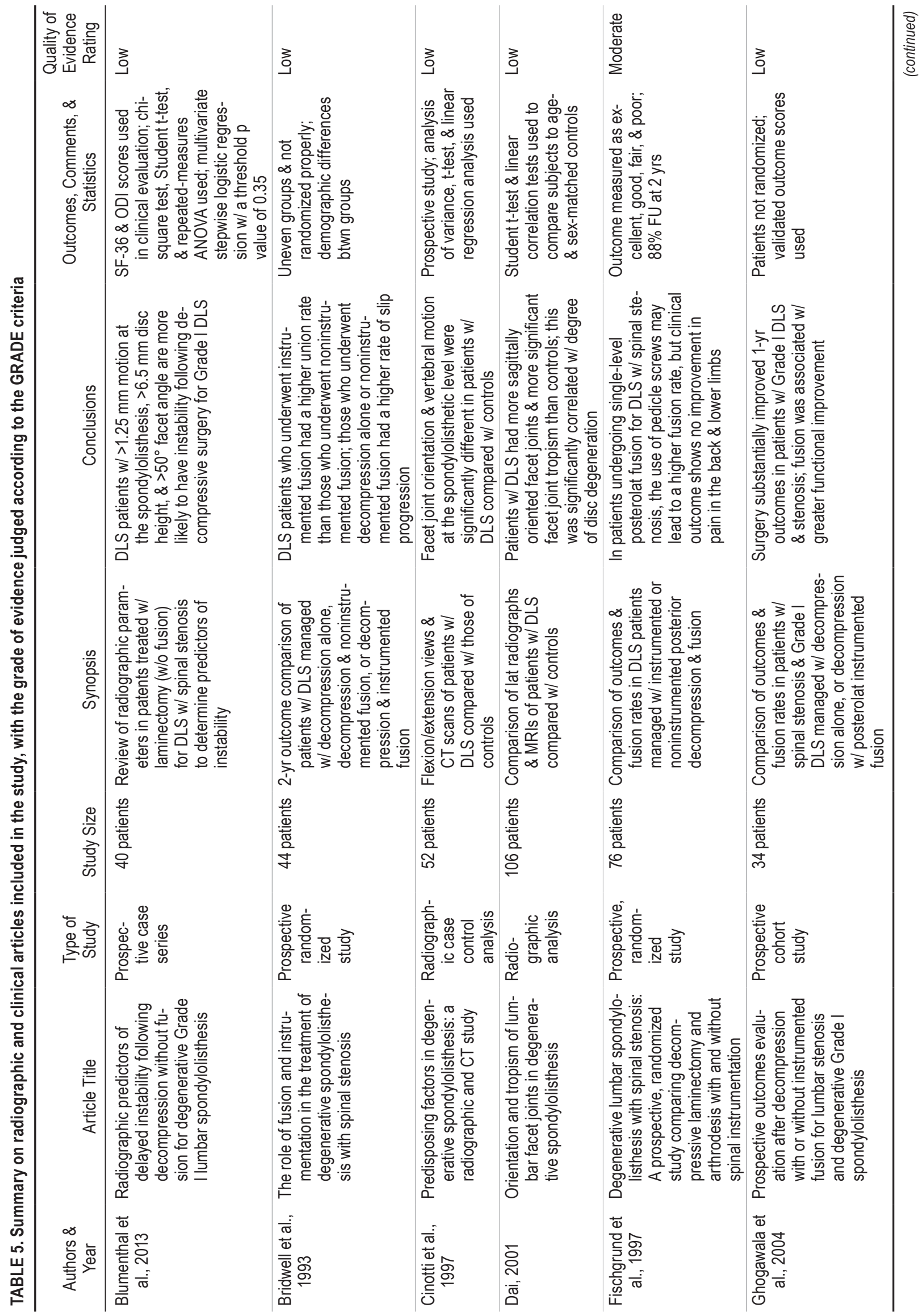




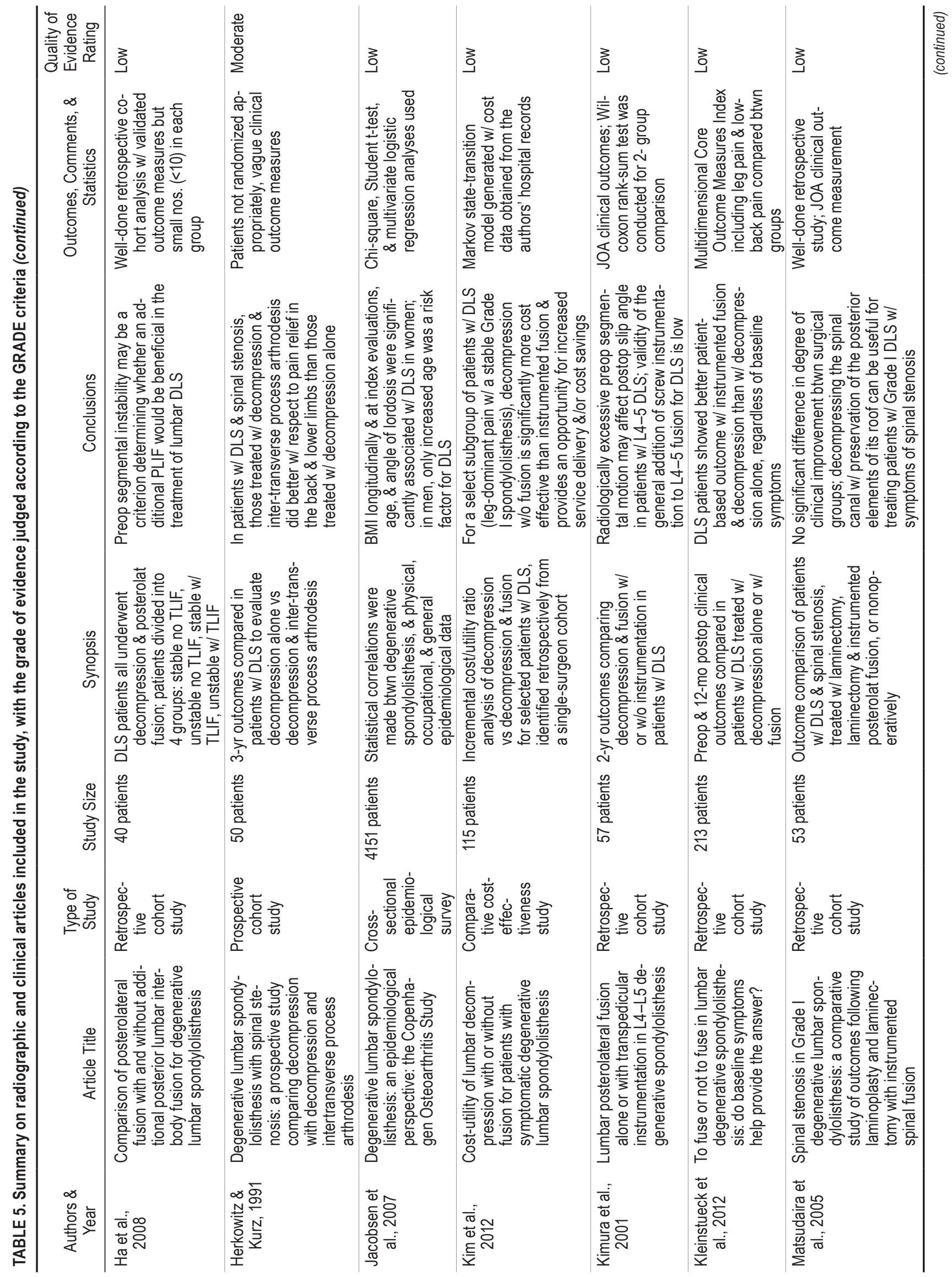




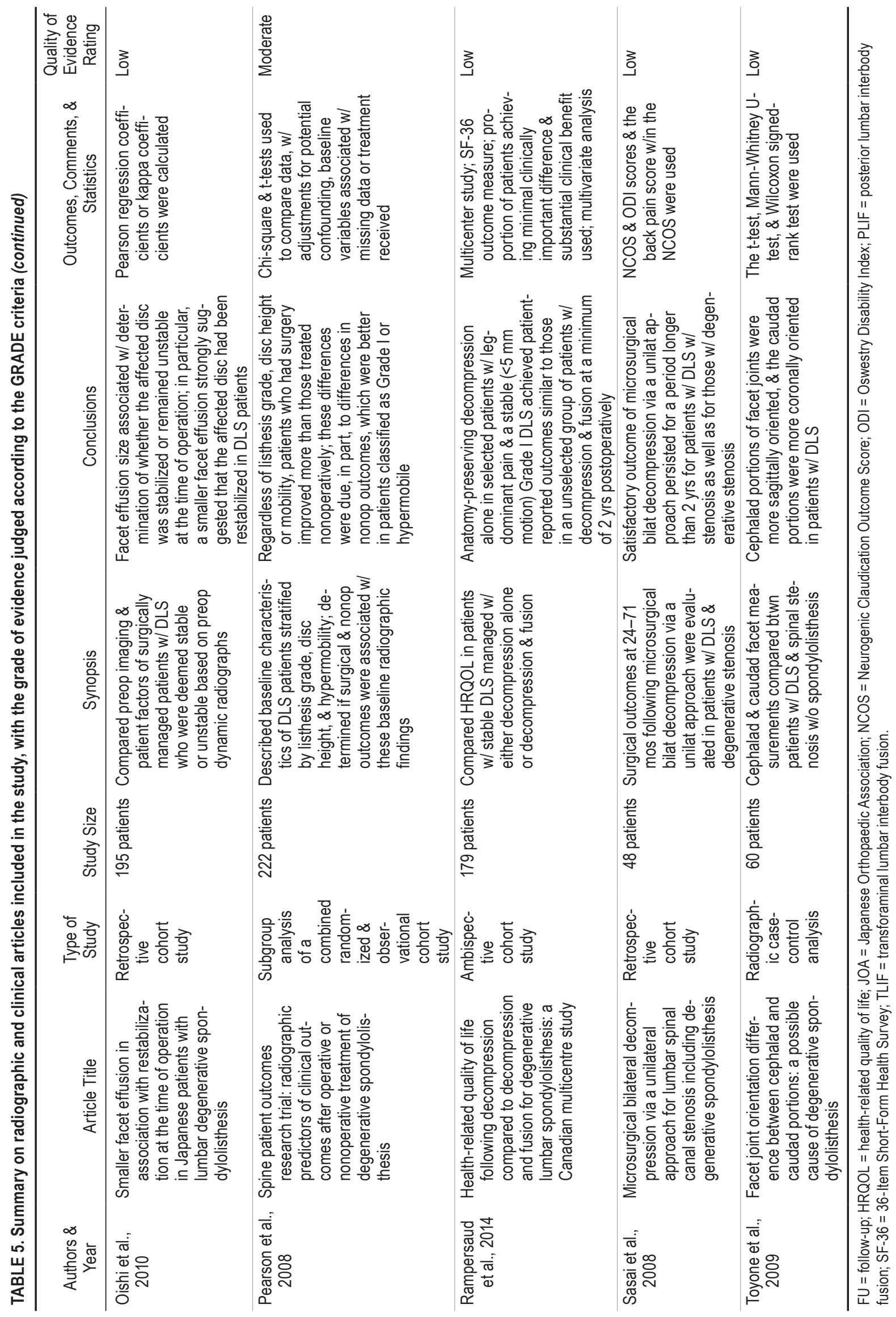


has suggested that stratifying patients based on stability is an important factor in treatment algorithms, and thus the importance of answering the above questions is amplified.

Our qualitative systematic review demonstrated only moderate to very low quality evidence related to these questions. However, we believe that the results are strong enough to adopt a qualitative method of defining DLS stability. Doing so supports our ideal of adopting an evidence-based medicine approach to treatment. Using clinical experience and the best available evidence, we must build decision aids or guidelines with which to move forward and obtain higher quality evidence.

The following parameters are probably predictors of stability in DLS: facet effusion, restabilization signs including disc height loss, disc angle change on dynamic radiographs, and the absence of low-back pain. The magnitude of their contribution can only be determined with appropriately powered prospective evaluation.

The segmental motion on dynamic radiographs is considered by most to be a reliable predictor of instability, yet there is little evidence or consensus on how this would best be assessed. Some studies that are clinically used and often cited did not meet our inclusion criteria. They used translation on dynamic radiographs as a marker of instability. Hanley described an unstable segment as one with $>$ $4 \mathrm{~mm}$ of translation or $>10^{\circ}$ of angular change on motion radiographs. ${ }^{26}$ Boden and Wiesel described ranges of normal translation on dynamic radiographs as $0 \%$ to $8 \%-9 \%$ and normal rotation as $0^{\circ}$ to $16^{\circ}-27^{\circ} .8$ White and Panjabi developed a checklist for clinical instability in the lumbar spine that included sagittal plane translation $>4.5 \mathrm{~mm}$ or $15 \%$ and sagittal plane rotation of $20^{\circ}$ at L4-5 or $25^{\circ}$ at L5-S1 on dynamic radiographs. ${ }^{60}$ Additionally, Posner et al. introduced the concept of threshold of stability on dynamic views as anterior translation $\leq 8 \%$, posterior translation $\leq 9 \%$, or angular rotation $\leq-9^{\circ}$ from L-1 to L-5 or $1^{\circ}$ at L5-S1. ${ }^{48}$ Working through this maze of parameters is futile if a high-level evidence-based conclusion is the goal. A qualitative proposal with face and content validity to be evaluated prospectively is the best we can do.

Identification of these parameters has allowed us to propose a preliminary degenerative spondylolisthesis instability classification (DSIC) scheme based on the preoperative assessment of stability. Facet joint effusion (very low to low quality evidence), restabilization signs and disc height loss (very low quality evidence), change in disc angle on flexion radiographs (low quality evidence), and leg-dominant versus back-dominant pain (very low to low quality evidence) were included in the proposed classification (Table 2). Other patient factors and sagittal orientation of the facets were not included, as their role in stability remains quite controversial based on current evidence. The DSIC should be used as a qualitative decision aid for surgeons to better evaluate DLS. The next phase for the classification scheme is reliability testing and criterion validity evaluation with future iterations to evolve into a quantitative decision aid.

There are inherent limitations to this study. Primarily, the quality of a systematic review is restricted by the quality of available literature. Much of the available evidence was low to very low quality, with a few studies graded as moderate quality evidence. This certainly lowers the strength of the recommendations, but it is the first systematic literature review regarding this question; therefore, it represents the highest-level evidence to date on grading DLS stability. Our results represent a starting point for studying these findings prospectively, so we can obtain higher-level research to quantify clinically relevant DLS stability.

Many clinical outcomes are measured up to 2 years posttreatment, but a paucity of long-term follow-up data appears in comparative studies on the surgical management of DLS. The answer to some specific outcomes, such as adjacent segment disease related to treatment choice, will not be seen until long-term outcome data become available. . $^{, 41,42,49}$

Finally, as a qualitative review, this study is naturally limited by researcher bias. To minimize this, we enlisted the expertise of 3 experienced spine surgeons and a biomedical engineer to evaluate the quality of the literature and reach a consensus on the recommendations.

Our surgical treatment recommendations are founded primarily on the theoretical and biomechanical demands of the surgical construct and the evidence from clinical studies. The surgical technique or construct used in DLS treatment should be established based on stability patterns and patient factors. Very stable DLS should not require fusion. A moderate degree of instability requires instrumented or noninstrumented fusion, and a highly unstable DLS would probably be best treated with a $360^{\circ}$ fusionthe construct offering the most stability. We have not discussed specific instrumentation types, nor have we explored more novel techniques such as minimally invasive surgery or interbody fusion as a stand-alone procedure.

While determining stability is critical in the evaluation and treatment of DLS, several other parameters deserve further appraisal for their roles in DLS pathology and treatment choices. Adjacent segment degeneration and proximal junctional kyphosis are not addressed in this study. Similarly, the utility of dynamic stabilization with interspinous stabilizers was outside the scope of our focused research and thus has not been explored in this review. Outcomes with segmental lordosis, reduction of translation, and instrumentation related to these pathologies and to health-related quality of life should be investigated further.

\section{Conclusions}

Spinal stability is an important factor to consider in the evaluation of patients with DLS. Facet effusion, restabilization signs including disc height loss, and disc angle change on dynamic radiographs are important parameters in the assessment of stability. In addition, clinical presentation with leg-dominant pain may be an important parameter to consider. Once the stability of a given segment is determined, the operative plan can be better gauged.

The proposed classification scheme in this study uses these parameters to help surgeons develop a method of preoperative evaluation to better stratify treatment options. From this assessment, preliminary surgical recommendations are based on stability type. These recommendations will be refined as reliability, validity, and prospective studies guide our understanding of this complex disease. 


\section{Acknowledgments}

We thank Andrew Pennington for his help with editing the final manuscript and Dean Giustini for his help with the literature search.

\section{References}

1. Agabegi SS, Majid K, Fischgrund JS, Vaccaro AR, Patel T: Can preoperative radiographic parameters be used to predict fusion in non-instrumented posterolateral fusion for degenerative spondylolisthesis? Spine (Phila Pa 1976) 36:E1709E1714, 2011

2. Ahn NU, Hammerberg KW, DeWald CJ, DeWald RL, Bergin CJ, An HS: Spondylolisthesis: classification, diagnosis, and natural history. Semin Spine Surg 15:112-124, 2003

3. Anderson DG, Limthongkul W, Sayadipour A, Kepler CK, Harrop JS, Maltenfort M, et al: A radiographic analysis of degenerative spondylolisthesis at the L4-5 level. J Neurosurg Spine 16:130-134, 2012

4. Berlemann U, Jeszenszky DJ, Bühler DW, Harms J: Facet joint remodeling in degenerative spondylolisthesis: an investigation of joint orientation and tropism. Eur Spine $\mathbf{J}$ 7:376-380, 1998

5. Berlemann U, Jeszenszky DJ, Bühler DW, Harms J: Mechanisms of retrolisthesis in the lower lumbar spine. A radiographic study. Acta Orthop Belg 65:472-477, 1999

6. Berlemann U, Jeszenszky DJ, Bühler DW, Harms J: The role of lumbar lordosis, vertebral end-plate inclination, disc height, and facet orientation in degenerative spondylolisthesis. J Spinal Disord 12:68-73, 1999

7. Blumenthal C, Curran J, Benzel EC, Potter R, Magge SN, Harrington JF Jr, et al: Radiographic predictors of delayed instability following decompression without fusion for degenerative Grade I lumbar spondylolisthesis. J Neurosurg Spine 18:340-346, 2013

8. Boden SD, Wiesel SW: Lumbosacral segmental motion in normal individuals. Have we been measuring instability properly? Spine (Phila Pa 1976) 15:571-576, 1990

9. Bridwell KH, Sedgewick TA, O’Brien MF, Lenke LG, Baldus $\mathrm{C}$ : The role of fusion and instrumentation in the treatment of degenerative spondylolisthesis with spinal stenosis. J Spinal Disord 6:461-472, 1993

10. Cagli S, Crawford NR, Sonntag VK, Dickman CA: Biomechanics of grade I degenerative lumbar spondylolisthesis. Part 2: treatment with threaded interbody cages/dowels and pedicle screws. J Neurosurg 94 (1 Suppl):51-60, 2001

11. Chen IR, Wei TS: Disc height and lumbar index as independent predictors of degenerative spondylolisthesis in middleaged women with low back pain. Spine (Phila Pa 1976) 34:1402-1409, 2009

12. Chen KX, Yang QY, Liu XC, Li HJ: [Treatment of degenerative lumbar spondylolisthesis through posterolateral fusion and fixation with pedicle screws.] Zhongguo Gu Shang 23:254-256, 2010 (Chinese)

13. Cho BY, Murovic JA, Park J: Imaging correlation of the degree of degenerative L4-5 spondylolisthesis with the corresponding amount of facet fluid. J Neurosurg Spine 11:614619,2009

14. Christensen FB, Thomsen K, Eiskjaer SP, Hansen ES, Fruensgaard S, Gelinick J, et al: [The effect of pedicle screw instrumentation on posterolateral spinal fusion. A prospective, randomized study with a two-year follow-up.] Ugeskr Laeger 161:1920-1925, 1999 (Danish)

15. Cinotti G, Postacchini F, Fassari F, Urso S: Predisposing factors in degenerative spondylolisthesis. A radiographic and CT study. Int Orthop 21:337-342, 1997

16. Crawford NR, Cagli S, Sonntag VK, Dickman CA: Biomechanics of grade I degenerative lumbar spondylolisthesis. Part 1: in vitro model. J Neurosurg 94 (1 Suppl):45-50, 2001
17. Dai D, Fang M, Shen G: A study on lumbar stability of degenerative spondylolisthesis treated with spine fine adjusting manipulation. Chinese J of Rehab Med 21:1110-1112, 2006

18. Dai LY: Orientation and tropism of lumbar facet joints in degenerative spondylolisthesis. Int Orthop 25:40-42, 2001

19. Dupuis PR, Yong-Hing K, Cassidy JD, Kirkaldy-Willis WH: Radiologic diagnosis of degenerative lumbar spinal instability. Spine (Phila Pa 1976) 10:262-276, 1985

20. Fischgrund JS, Mackay M, Herkowitz HN, Brower R, Montgomery DM, Kurz LT: 1997 Volvo Award Winner in Clinical Studies. Degenerative lumbar spondylolisthesis with spinal stenosis: a prospective, randomized study comparing decompressive laminectomy and arthrodesis with and without spinal instrumentation. Spine (Phila Pa 1976) 22:2807-2812, 1997

21. Friberg O: Instability in spondylolisthesis. Orthopedics 14:463-465, 1991

22. Ghogawala Z, Benzel EC, Amin-Hanjani S, Barker FG II, Harrington JF, Magge SN, et al: Prospective outcomes evaluation after decompression with or without instrumented fusion for lumbar stenosis and degenerative Grade I spondylolisthesis. J Neurosurg Spine 1:267-272, 2004

23. Grobler LJ, Robertson PA, Novotny JE, Pope MH: Etiology of spondylolisthesis. Assessment of the role played by lumbar facet joint morphology. Spine (Phila Pa 1976) 18:80-91, 1993

24. Ha KY, Na KH, Shin JH, Kim KW: Comparison of posterolateral fusion with and without additional posterior lumbar interbody fusion for degenerative lumbar spondylolisthesis. J Spinal Disord Tech 21:229-234, 2008

25. Hammouri QM, Haims AH, Simpson AK, Alqaqa A, Grauer JN: The utility of dynamic flexion-extension radiographs in the initial evaluation of the degenerative lumbar spine. Spine (Phila Pa 1976) 32:2361-2364, 2007

26. Hanley EN Jr: The indications for lumbar spinal fusion with and without instrumentation. Spine (Phila Pa 1976) 20 (24 Suppl):143S-153S, 1995

27. Hasegewa K, Kitahara K, Hara T, Takano K, Shimoda H: Biomechanical evaluation of segmental instability in degenerative lumbar spondylolisthesis. Eur Spine J 18:465-470, 2009

28. Hasegawa K, Kitahara K, Shimoda H, Hara T: Facet joint opening in lumbar degenerative diseases indicating segmental instability. J Neurosurg Spine 12:687-693, 2010

29. Herkowitz HN, Kurz LT: Degenerative lumbar spondylolisthesis with spinal stenosis. A prospective study comparing decompression with decompression and intertransverse process arthrodesis. J Bone Joint Surg Am 73:802-808, 1991

30. Jacobsen S, Sonne-Holm S, Rovsing H, Monrad H, Gebuhr P: Degenerative lumbar spondylolisthesis: an epidemiological perspective: the Copenhagen Osteoarthritis Study. Spine (Phila Pa 1976) 32:120-125, 2007

31. Kanayama M, Hashimoto T, Shigenobu K, Oha F, Ishida T, Yamane S: Intraoperative biomechanical assessment of lumbar spinal instability: validation of radiographic parameters indicating anterior column support in lumbar spinal fusion. Spine (Phila Pa 1976) 28:2368-2372, 2003

32. Kelleher MO, Timlin M, Persaud O, Rampersaud YR: Success and failure of minimally invasive decompression for focal lumbar spinal stenosis in patients with and without deformity. Spine (Phila Pa 1976) 35:E981-E987, 2010

33. Kim S, Mortaz Hedjri S, Coyte PC, Rampersaud YR: Costutility of lumbar decompression with or without fusion for patients with symptomatic degenerative lumbar spondylolisthesis. Spine J 12:44-54, 2012

34. Kimura I, Shingu H, Murata M, Hashiguchi H: Lumbar posterolateral fusion alone or with transpedicular instrumentation in L4-L5 degenerative spondylolisthesis. J Spinal Disord 14:301-310, 2001 
35. Kirkaldy-Willis WH, Farfan HF: Instability of the lumbar spine. Clin Orthop Relat Res (165):110-123, 1982

36. Kleinstueck FS, Fekete TF, Mannion AF, Grob D, Porchet F, Mutter U, et al: To fuse or not to fuse in lumbar degenerative spondylolisthesis: do baseline symptoms help provide the answer? Eur Spine J 21:268-275, 2012

37. Kornblum MB, Fischgrund JS, Herkowitz HN, Abraham DA, Berkower DL, Ditkoff JS: Degenerative lumbar spondylolisthesis with spinal stenosis: a prospective long-term study comparing fusion and pseudarthrosis. Spine (Phila Pa 1976) 29:726-734, 2004

38. Kwon BK, Hilibrand AS, Malloy K, Savas PE, Silva MT, Albert TJ, et al: A critical analysis of the literature regarding surgical approach and outcome for adult low-grade isthmic spondylolisthesis. J Spinal Disord Tech 18 (Suppl):S30 S40, 2005

39. Lattig F, Fekete TF, Grob D, Kleinstück FS, Jeszenszky D, Mannion AF: Lumbar facet joint effusion in MRI: a sign of instability in degenerative spondylolisthesis? Eur Spine J 21:276-281, 2012

40. Laus M, Tigani D, Alfonso C, Giunti A: Degenerative spondylolisthesis: lumbar stenosis and instability. Chir Organi Mov 77:39-49, 1992

41. Martin CR, Gruszczynski AT, Braunsfurth HA, Fallatah SM, O'Neil J, Wai EK: The surgical management of degenerative lumbar spondylolisthesis: a systematic review. Spine (Phila Pa 1976) 32:1791-1798, 2007

42. Matsudaira K, Yamazaki T, Seichi A, Takeshita K, Hoshi K, Kishimoto J, et al: Spinal stenosis in grade I degenerative lumbar spondylolisthesis: a comparative study of outcomes following laminoplasty and laminectomy with instrumented spinal fusion. J Orthop Sci 10:270-276, 2005

43. Matsunaga S, Ijiri K, Hayashi K: Nonsurgically managed patients with degenerative spondylolisthesis: a 10- to 18-year follow-up study. J Neurosurg 93 (2 Suppl):194-198, 2000

44. Matsunaga S, Sakou T, Morizono Y, Masuda A, Demirtas AM: Natural history of degenerative spondylolisthesis. Pathogenesis and natural course of the slippage. Spine (Phila Pa 1976) 15:1204-1210, 1990

45. Minamide A, Yoshida M, Yamada H, Hashizume H, Nakagawa Y, Kawai M, et al: Factors affected to clinical outcomes of decompression surgery without fusion for degenerative lumbar spondylolisthesis. Spine: Affiliated Society Meeting Abstracts. October, 2010. (Poster) (http:// journals.lww.com/spinejournalabstracts/Citation/2010/10001/ FACTORS_AFFECTED_TO_CLINICAL_OUTCOMES_ OF.267.aspx) [Accessed March 8, 2015]

46. Oishi Y, Murase M, Hayashi Y, Ogawa T, Hamawaki J: Smaller facet effusion in association with restabilization at the time of operation in Japanese patients with lumbar degenerative spondylolisthesis. J Neurosurg Spine 12:88-95, 2010

47. Pearson AM, Lurie JD, Blood EA, Frymoyer JW, Braeutigam $\mathrm{H}, \mathrm{An} \mathrm{H}$, et al: Spine patient outcomes research trial: radiographic predictors of clinical outcomes after operative or nonoperative treatment of degenerative spondylolisthesis. Spine (Phila Pa 1976) 33:2759-2766, 2008

48. Posner I, White AA III, Edwards WT, Hayes WC: A biomechanical analysis of the clinical stability of the lumbar and lumbosacral spine. Spine (Phila Pa 1976) 7:374-389, 1982

49. Rampersaud YR, Fisher C, Yee A, Dvorak MF, Finkelstein J, Wai E, et al: Health-related quality of life following decompression compared to decompression and fusion for degenerative lumbar spondylolisthesis: a Canadian multicentre study. Can J Surg 57:E126-E133, 2014

50. Resnick DK, Choudhri TF, Dailey AT, Groff MW, Khoo L, Matz PG, et al: Guidelines for the performance of fusion procedures for degenerative disease of the lumbar spine. Part 9: fusion in patients with stenosis and spondylolisthesis. J Neurosurg Spine 2:679-685, 2005
51. Resnick DK, Watters WC III, Sharan A, Mummaneni PV, Dailey AT, Wang JC, et al: Guideline update for the performance of fusion procedures for degenerative disease of the lumbar spine. Part 9: lumbar fusion for stenosis with spondylolisthesis. J Neurosurg Spine 21:54-61, 2014

52. Sasai K, Umeda M, Maruyama T, Wakabayashi E, Iida H: Microsurgical bilateral decompression via a unilateral approach for lumbar spinal canal stenosis including degenerative spondylolisthesis. J Neurosurg Spine 9:554-559, 2008

53. Satomi K, Hirabayashi K, Toyama Y, Fujimura Y: A clinical study of degenerative spondylolisthesis. Radiographic analysis and choice of treatment. Spine (Phila Pa 1976) 17:1329-1336, 1992

54. Schünemann HJ, Jaeschke R, Cook DJ, Bria WF, El-Solh AA, Ernst A, et al: An official ATS statement: grading the quality of evidence and strength of recommendations in ATS guidelines and recommendations. Am J Respir Crit Care Med 174:605-614, 2006

55. Scioscia T, Wallach C, Wang JC: Fusion vs interspinous device for lumbar spondylolisthesis. SpineLine Online 9:19-23, 2008

56. Sengupta DK, Herkowitz HN: Degenerative spondylolisthesis: review of current trends and controversies. Spine (Phila Pa 1976) 30 (6 Suppl):S71-S81, 2005

57. Toyone T, Ozawa T, Kamikawa K, Watanabe A, Matsuki K, Yamashita T, et al: Facet joint orientation difference between cephalad and caudad portions: a possible cause of degenerative spondylolisthesis. Spine (Phila Pa 1976) 34:2259-2262, 2009

58. Watters WC III, Bono CM, Gilbert TJ, Kreiner DS, Mazanec DJ, Shaffer WO, et al: An evidence-based clinical guideline for the diagnosis and treatment of degenerative lumbar spondylolisthesis. Spine J 9:609-614, 2009

59. Weinstein JN, Lurie JD, Tosteson TD, Zhao W, Blood EA, Tosteson AN, et al: Surgical compared with nonoperative treatment for lumbar degenerative spondylolisthesis. Fouryear results in the Spine Patient Outcomes Research Trial (SPORT) randomized and observational cohorts. J Bone Joint Surg Am 91:1295-1304, 2009

60. White AA, Panjabi MM: Clinical Biomechanics of the Spine, ed 2. Philadelphia: Lippincott Williams \& Wilkins, 1990

\section{Author Contrtibutions}

Conception and design: Fisher, Simmonds. Acquisition of data: Simmonds, Melnyk. Analysis and interpretation of data: Fisher, Simmonds, Rampersaud, Dvorak. Drafting the article: Simmonds, Melnyk. Critically revising the article: all authors. Reviewed submitted version of manuscript: Simmonds, Rampersaud, Dvorak, Dea, Melnyk. Approved the final version of the manuscript on behalf of all authors: Fisher. Study supervision: Fisher.

\section{Supplemental Information}

\section{Previous Presentation}

Portions of this work were presented in a podium presentation at the Annual Meeting of the Canadian Spine Society held in Mont Tremblant, QC, Canada, on March 1, 2013.

\section{Correspondence}

Charles G. Fisher, Blusson Spinal Cord Centre, 6th Fl., 818 W. 10th Ave., Vancouver, BC V5Z 1M9, Canada. email: charles. fisher@vch.ca. 